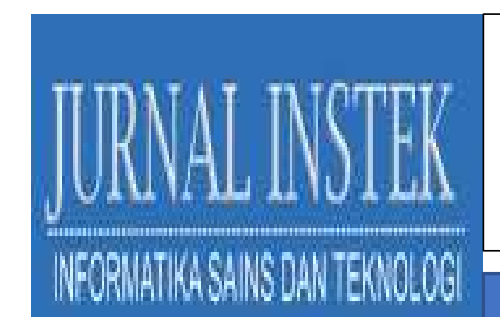

Volume 6 Nomor. 1, April 2021

P-ISSN : 2541-1179, E-ISSN : 2581-1711

Ojs :http://journal.uin-alauddin.ac.id/index.php/instek/index

Email : instek@uin-alauddin.ac.id

\title{
IMPLEMENTASI ALGORITMA GENETIKA DALAM ELIMINASI BENTROKAN JADWAL PERKULIAHAN DI POLITEKNIK UNISMA MALANG
}

\section{NUR SHOFIYATI ${ }^{1}$, MUH. ULINNUHA MUSTHOFA ${ }^{2}$,ADITYA MAHENDRA PUTRA ${ }^{3}$}

Teknik Mesin, Politeknik Unisma Malang ${ }^{1,2}$, BBIB Singosari ${ }^{3}$ Email :,nshofiyati@gmail.com ${ }^{1}$, ulinnuhamusthofa.polisma@gmail.com², adityamahendra@pertanian.go.id ${ }^{3}$

\begin{abstract}
ABSTRAK
Penelitian ini bertujuan memperoleh efisiensi penyusunan jadwal dengan mengeliminasi bentrokan jadwal menggunakan metode algoritma genetika. Metode penelitian diawali dengan pengumpulan data awal dimana ditemukan permasalaham bentrokan ruang, bentrokan kelas dan bentrokan dosen. Permasalahan tersebut digunakan sebagai dasar perumusan nilai fitness. Nilai fitness dalam penelitian ini deitentukan $1 /(1+\mathrm{BD}+\mathrm{BK}+\mathrm{BR})$. Algoritma genetika penelitian ini menggunakan 6 kromosom agar mendapatkan solusi optimal. Nilai crossover rate di atur sebesar $80 \%$, serta mutation rate dikontrol pada nilai 0.3 atau $30 \%$ agar pemrosesan tidak berlangsung lama. Hasil penelitian ini berupa aplikasi penyusunan jadwal berbasis android yang menerapkan algoritma genetika. Berdasarkan uji coba aplikasi menunjukkan bahwa hasil penjadwalan dengan algoritma genetika mampu mengeliminasi bentrokan jadwal.
\end{abstract}

Kata kunci - Genetika, Fitness, Jadwal

\section{PENDAHULUAN}

Penentuan jadwal kuliah merupakan bagian penting dalam persiapan proses pembelajaran awal semester khususnya di Politeknik Unisma. Secara kapasitas Politeknik Unisma Malang memiliki 3 program studi dengan ruang kelas teori, laboratorium, dan bengkel. Selama ini penyusunan jadwal dilakukan secara manual dengan membuat tabel jadwal berisi berbagai macam komponen. Beberapa komponen yang perlu dipertimbangkan dalam proses penyusunan jadwal diantaranya jam operasional, jumlah kelas, kesediaan dosen, kapasitas ruang bengkel atau lab. Selain itu proses pertimbangan penentuan jadwal membutuhkan waktu yang lama karena harus berkomunikasi dengan dosen (Lukas dkk, 2012), serta mempertimbangkan kondisi waktu operasional dan kapasitas kelas. Kerumitan 


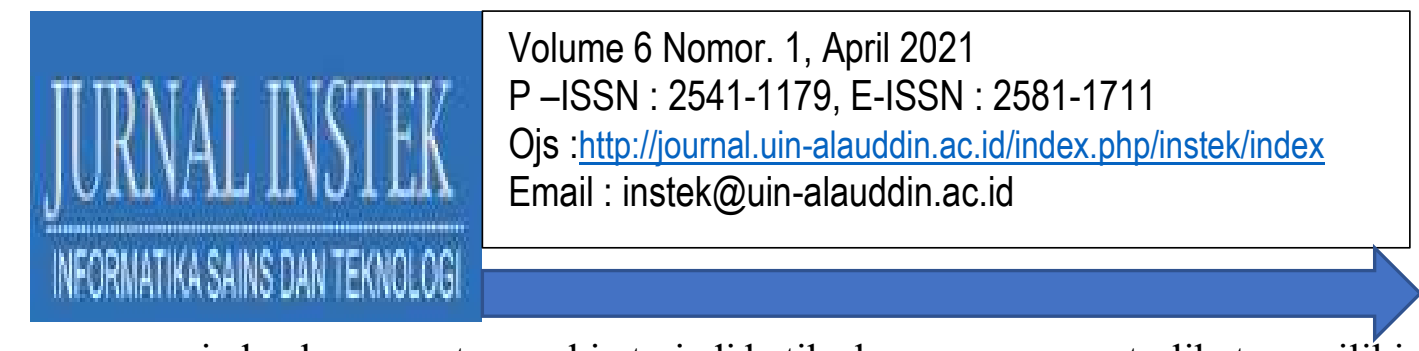

proses penjadwalan sangat mungkin terjadi ketika komponen yang terlibat memiliki jumlah yang besar (Ridwan, 2016).

Banyaknya jumlah komponen penyusun jadwal di politeknik unisma ternyata menimbulkan masalah baru. Masalah pertama ketika ada jadwal dengan ruang yang sama di satu waktu sehingga menimbulkan crash pada pengguna ruang. Masalah kedua adalah ketika ada kelas yang sama di satu waktu dan tempat berbeda. Dan yang terakhir adalah ketika ada dosen pengajar sama di satu waktu dan tempat yang berbeda. Permasalahan tersebut muncul tidak lain karena setiap komponen memiliki aturan dan batasan-batasan tertentu, dimana ketika proses penyusunannya secara manual akan membutuhkan pertimbangan dan waktu yang cukup panjang. Oleh karena itu peneliti mengusulkan untuk membangun sistem penjadwalan yang dapat berjalan dengan cepat, tepat tidak keluar dari aturan-aturan yang telah ditetapkan

Berkembangnya teknologi informasi dan ilmu komputasi telah banyak digunakan untuk memecahkan permasalahan-permasalahan kompleks penyusunan jadwal seperti jadwal produksi, jadwal layanan rumah sakit, termasuk penjadwalan matakuliah dalam dunia akademik. Salah satu metode yang saat ini banyak diteliti adalah metode Genetika. Metode ini dapat menangani kapasitas pencarian yang kompleks dan luas dalam sebuah pemecahan masalah dengan batas yang dapat ditentukan (Al-Jarrahdkk, 2017; Shukla, dkk, 2015). Algoritma Genetika mengadaptasi dari konsep teori evolusi yang dikemukakan oleh charles darwin. Algoritma ini menerapkan seleski data dengan kriteria nilai fitness . Nilai fitnes berperan penting dalam membentuk data baru yang lebih baik dari sebelumnya sehingga memberikan hasil akurat (Radliya, 2016). Untuk meningkatkan peluang akurasi fitness $100 \%$ algoritma ini juga menggunakan tahapan mutasi untuk mencegah terjadinya konvergensi prematur (Ridwan,2016).

Penelitian terdahulu goritma genetika kemudahan dalam mengelola jadwalan kuliah dengan tepat sesuai kesiapan waktu dosen mengajar (Laksono dkk, 2016). Selain memberikan kemudahan pengelolaan jadwal, implementasi algoritma 


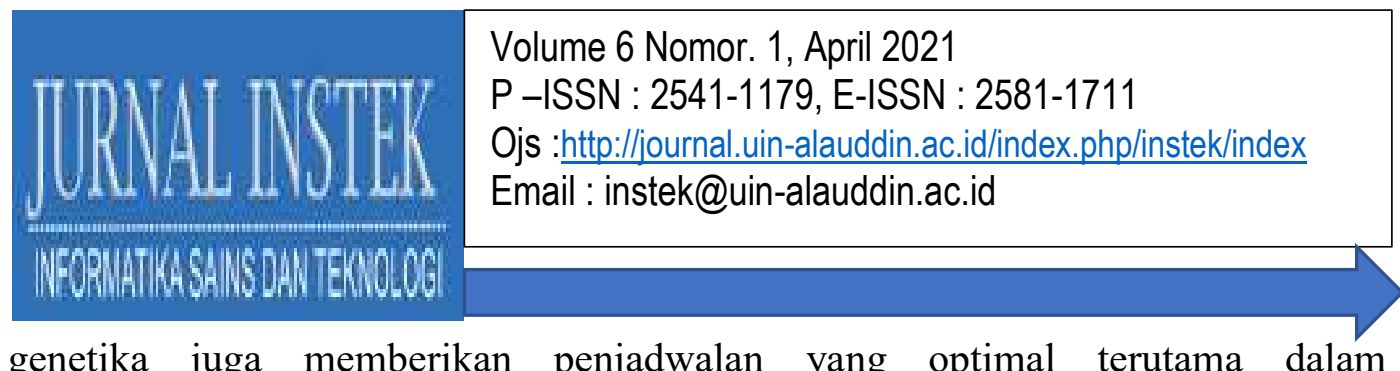

genetika juga memberikan penjadwalan yang optimal terutama dalam meminimalisir benturan jadwal (Yusuf \& Wiji, 2019). Algoritma genetika bersifat fleksibel sehingga dapat memberikan solusi yang cukup baik diterapkan pada berbagai model permasalahan (Yadav \& Sohal, 2017). Kelebihan-kelebihan yang dimiliki oleh algoritma genetika menarik perhatian peneliti untuk dapat diterapkan dalam pemecahan masalah proses penyusunan jadwal perkuliahan khususnya di politeknik unisma malang

\section{METODE PENELITIAN}

\section{Pengumpulan Data}

Pengumpulan data meliputi komponen-komponen yang terkait penyusunan jadwal. Metode yang dilakukan berupa Wawancara terhadap, Ketua Program Studi (Kaprodi), Kepala BAUK, Kepala Laboratorium (Kalab). Prosedur penyusunan jadwal dimulai dari plot jadwal dosen oleh masingmasing kaprodi dan Kalab. Hasil plot kaprodi dan kalab diolah Kepala BAUK menghasilkan deskripisi jadwal diuraikan sebagai berikut :

a. Data Jurusan, di politeknik unisma terdapat 3 jurusan diantaranya teknik mesin, teknik listrik dan teknik rekayasa komputer jaringan.

b. Data Ruang terdiri dari ruang kelas teori sejumlah 6 kelas, 2 ruang bengkel prodi , 1 ruang bengkel bersama, 4 ruang laboratorium

c. Data Dosen meliputi data dosen, data identitas dosen. beberapa dosen juga mengampu matakuliah lintas jurusan

d. Data matakuliah meliputi data nama matakuliah, kode matakuliah, jumlah sks, sesi dan semester

Data tersebut diolah menjadi sebuah daftar jadwal matakuliah dengan format, hari, ruang, sesi (jam perkuliahan), matakuliah untuk. Contoh sampel jadwal hasil penyusunan secara manual dilihat pada tabel dibawah :

Tabel 1. Sampel jadwal matakuliah

\begin{tabular}{lccl}
\hline Hari & Ruang & Jam & Mata Kuliah \\
\hline Senin & D3.02 & 1 & Bahasa Inggris 1 \\
\hline
\end{tabular}


Volume 6 Nomor. 1, April 2021

P-ISSN : 2541-1179, E-ISSN : 2581-1711

Ojs :http://journal.uin-alauddin.ac.id/index.php/instek/index

Email : instek@uin-alauddin.ac.id

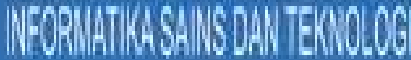

\begin{tabular}{llll}
\hline Senin & D3.02 & 1 & Ilmu Bahan \\
\hline Senin & D3.03 & 3 & Agama Islam 1 \\
\hline Senin & D3.04 & 3 & Bahasa Inggris 1 \\
\hline Senin & Lab TRKJ & 4 & Jaringan Komputer \\
\hline Senin & Lab TRKJ & 4 & Jaringan Komputer \\
\hline$\ldots . .$. & & & \\
\hline
\end{tabular}

Hasil sampel jadwalan matakuliah secara manual tersebut memunculkan beberapa permasalahan bentrokan seperti dijelaskan pada bag pendahuluan.

\section{Alur Algoritma Genetika pada Penjadwalan Matakuliah}

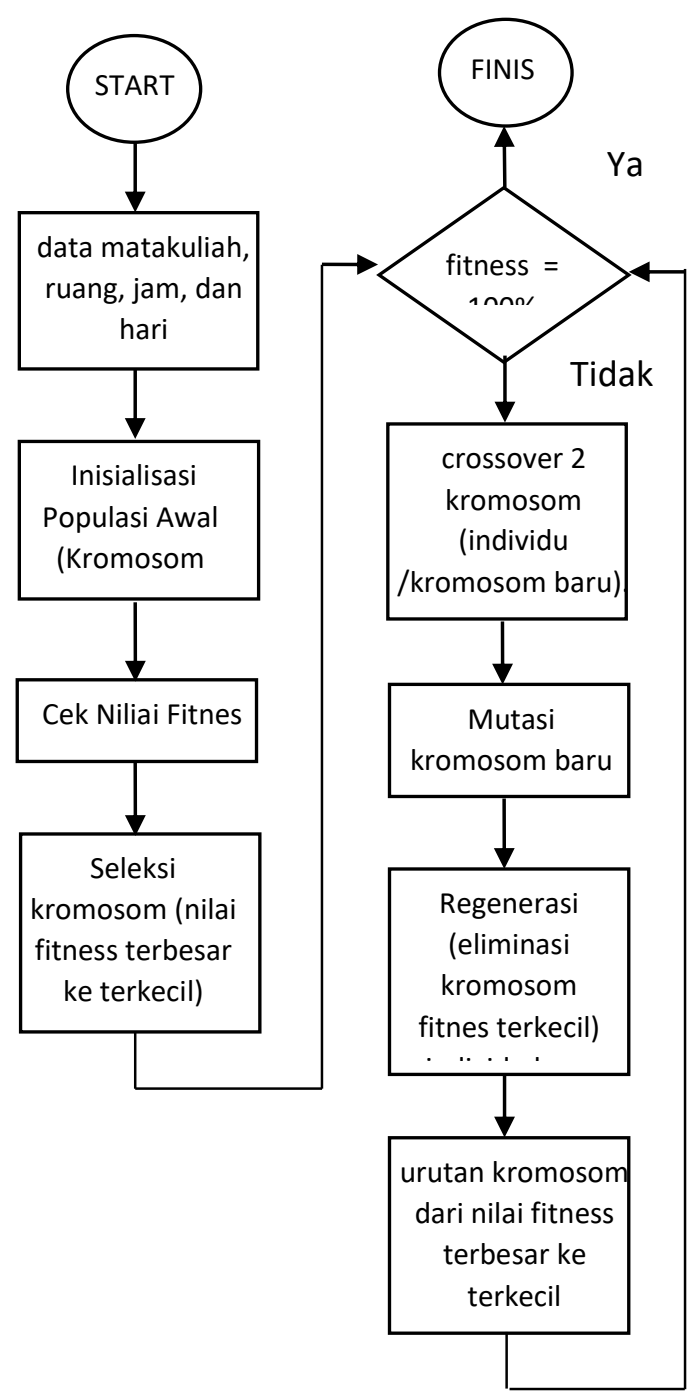

Gambar 1. Algoritma Genetika 
Volume 6 Nomor. 1, April 2021

P-ISSN : 2541-1179, E-ISSN : 2581-1711

Ojs :http://journal.uin-alauddin.ac.id/index.php/instek/index

Email : instek@uin-alauddin.ac.id

III. HASIL DAN PEMBAHASAN

\section{A. IMPLEMENTASI ALGORITMA GENETIKA:}

\section{Membuat Kromosom}

Kromosom (Individu) adalah gabungan dari gen-gen \{Hari, Jam, Ruang, Matakuliah\} dengan jumlah gen sesuai dengan matakuliah. Banyaknya kromosom akan mempengaruhi proses untuk mendapatkan nilai sempurna. Banyaknya kromosom yang optimal diset sebanyak 6 kromosom untuk menghindari pemroses data yang lama.

Kromosom $1=\{[$ Senin, R1, 1, 1001], [Senin, R2, 5, 1002], .. $\}$

Gambar 2. Sampel Kromosom

Pada gambar 2 data senin menunjukkan hari, R1 menunjukkan ruang, 1 menunjukkan sesi, dan 1001 menunjukkan matakuliah.

\section{Penentuan Fitness}

Fitness dalam penelitian berfungsi menyelesaikan permasalahan bentrokan jadwal yang ditemukan saat pengumpulan data, diantaranya :

a. Adanya bentrokan ruang (jadwal dengan ruang dan waktu yang sama).

b. Adanya bentrokan kelas (kelas di waktu sama dan tempat berbeda).

c. Adanya bentrokan dosen (dosen pengajar sama di satu waktu dan tempat yang berbeda).

Penentuan fungsi fitness dirumuskan berdasarkan suatu permasalahan dan representasi data yang digunakan dalam sebuah studi kasus (Sari, 2019). Berdasarkan 3 permasalahan tersebut untuk mempertahankan kromosom dengan nilai fitnes tinggi rumus fitness yang digunakan :

Fitness $=1 /(1+\mathrm{BD}+\mathrm{BK}+\mathrm{BR})$

$\mathrm{BD}=$ "Bentrokan Dosen"

BK = "Bentrokan Kelas/Jurusan"

$\mathrm{BR}=$ "Bentrokan Ruang" 
Berdasarkan perhitungan tersebut, diketahui nilai fitness sempurna adalah 1, sehingga semakin banyak data yang bentrok maka fitness semakin kecil.

\section{Seleksi}

Seleksi dilakukan dengan cara mengurutkan fitness kromosom mulai dari yang terbesar sampai terkecil dengan penentuan fitness seperti yang sudah diterangkan di poin pertama.

\section{Crossover (KawinSilang)}

Crossover atau kawin silang dalam penelitian ini adalah proses pertukaran gen antara 2 kromosom (individu) sehingga menghasilkan kromosom (individu) dengan gen baru. Dalam proses ini diatur nilai crossover rate untuk kromosom (individu) yang akan disilangkan. Crossover rate digunakan untuk menentukan banyaknya kromosom (individu) yang melakukan crossover. Nilai crossover rate yang diset pada program adalah sebesar $80 \%$ yang berarti sebanyak $80 \%$ kromosom akan melakukan crossover. Dari kawinsilang itu setiap pasang akan mempunyai 2 individu baru dengan gen baru dari gabungan gen dari pasangan tersebut.

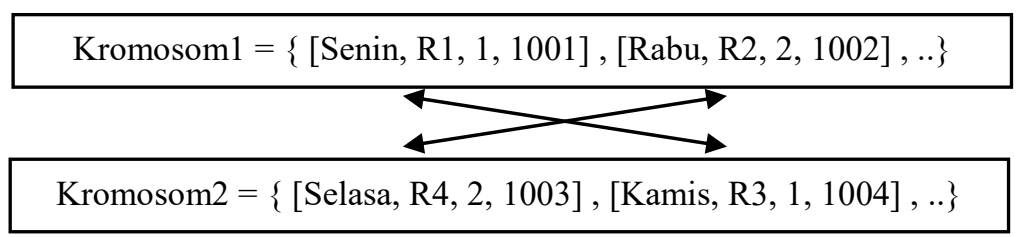

Gambar 3. Sample Tahapan Crossover

\section{Mutasi}

Mutasi merupakan proses pembaruan/perkembangan gen, dimana gen (Senin, R1, 1, 1001) hanya akan dirubah nilai hari, ruang, dan sesinya saja sehingga membentuk gen lain secara random (Selasa, R4, 2, 1001). Kecepatan mutasi (mutation rate) ini sudah dekendalikan di awal dengan 


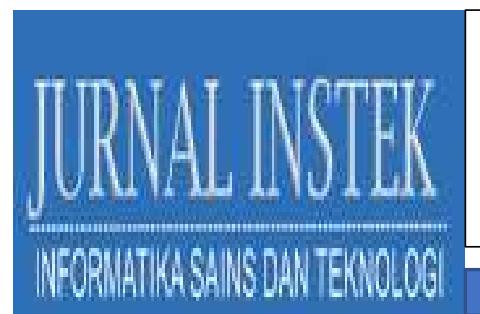

Volume 6 Nomor. 1, April 2021

P-ISSN : 2541-1179, E-ISSN : 2581-1711

Ojs :http://journal.uin-alauddin.ac.id/index.php/instek/index

Email : instek@uin-alauddin.ac.id

nilai 0.3 atau $30 \%$. Hal ini untuk menghindari jumlah mutasi gen yang terlalu banyak yang akan menimbulkan proses komputasi yang lama.

Kromosom1 Baru $=\{[$ Senin, R1, 1, 1001] $,[$ Senin, R3, 1, 1004 $], .\}$.

Mutasi Kromosom 1 Baru $=\{[$ Selasa, R4, 2, 1001],$[$ Senin, R2, 3, 1004] ,.. $\}$

Gambar 4. Sample Tahapan Mutasi

\section{Regenerasi}

Regenerasi merupakan proses penggantian kromosom (individu) lama ke kromosom (individu) generasi terbaru. Regenerasi ini diatur berdasarkan tingkat fitness kromosom (individu) tersebut, kromosom (individu) dengan nilai fitness terkecil akan digantikan dengan individu baru. Kromosom dengan nilai fitnes terkecil akan dikembalikan pada proses crossover, dan akan terus berulang sampai semua kromosom menemukan nilai fitnes 1 yang artinya sudah tidak lagi terjadi bentrokan jadwal

\section{B. Tampilan Program Penjadwalan dengan Algortima Genetika}

\section{Tampilan Halaman Awal}

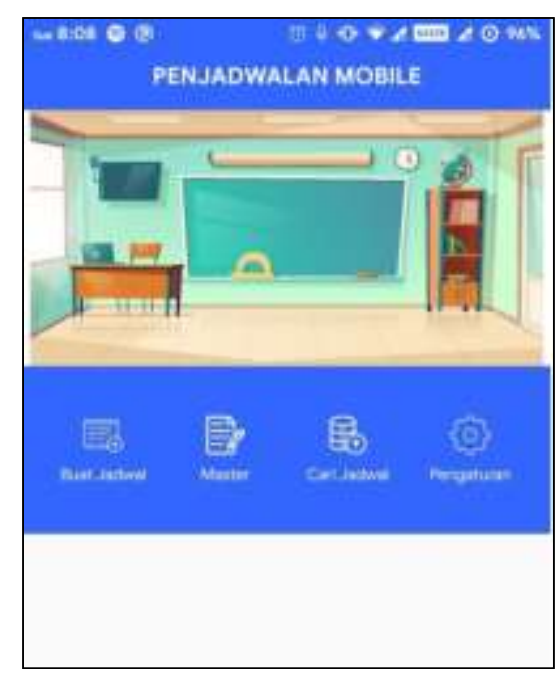

Gambar 5. Tampilan Halaman Utama

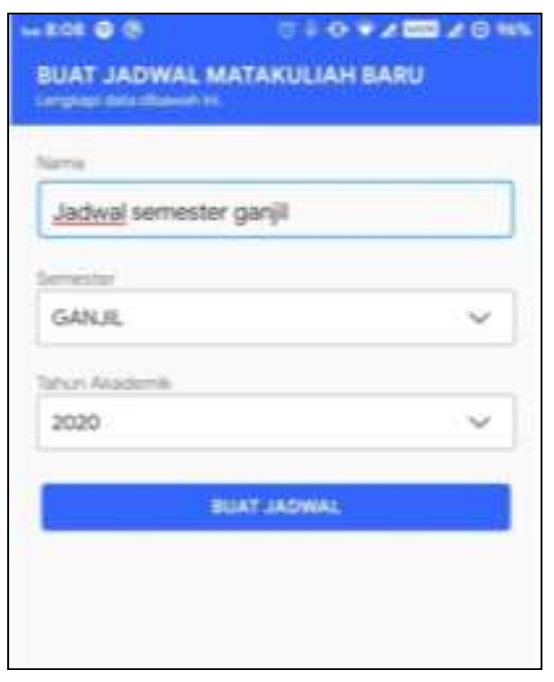

Gambar 6. Tampilan Buat Jadwal 
Volume 6 Nomor. 1, April 2021

P-ISSN : 2541-1179, E-ISSN : 2581-1711

Ojs :http://journal.uin-alauddin.ac.id/index.php/instek/index Email : instek@uin-alauddin.ac.id

Implementasi algoritma genetika diterapkan pada aplikasi android yang sudah dijalankan pada sistem cloud. Pada halaman utama aplikasi ini ditampilkan keseluruhan menu (gambar5) serta pembuatan jadwal baru (gambar 6), dan menu input (master data).

\section{Tampilan Halaman Input Data}

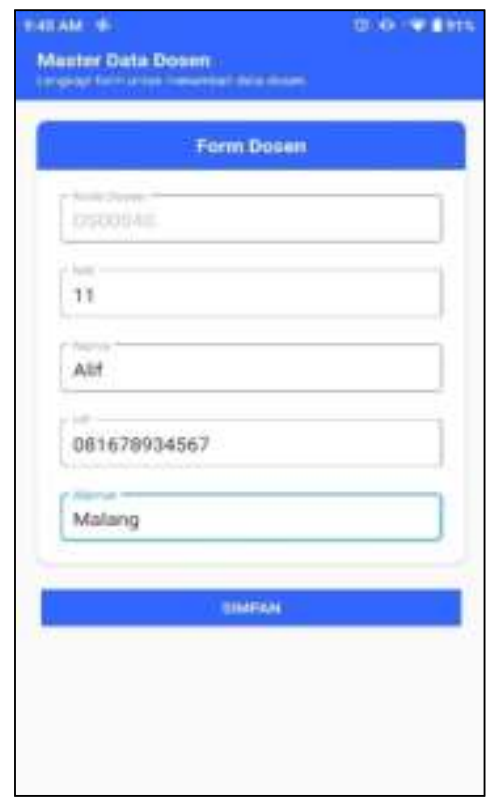

Gambar 7. Tampilan Input Dosen

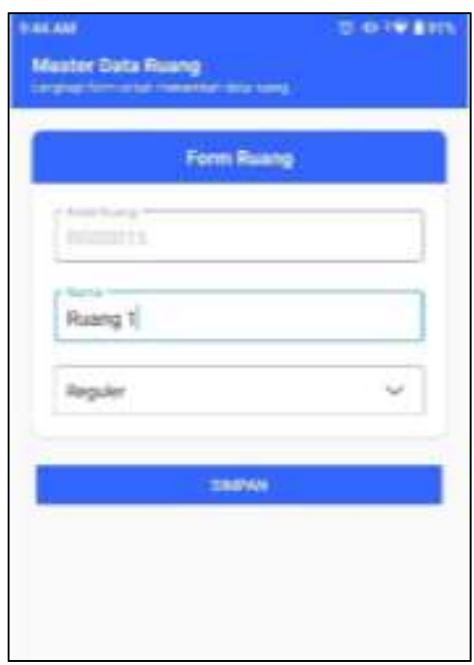

Gambar 9. Tampilan Input Ruang

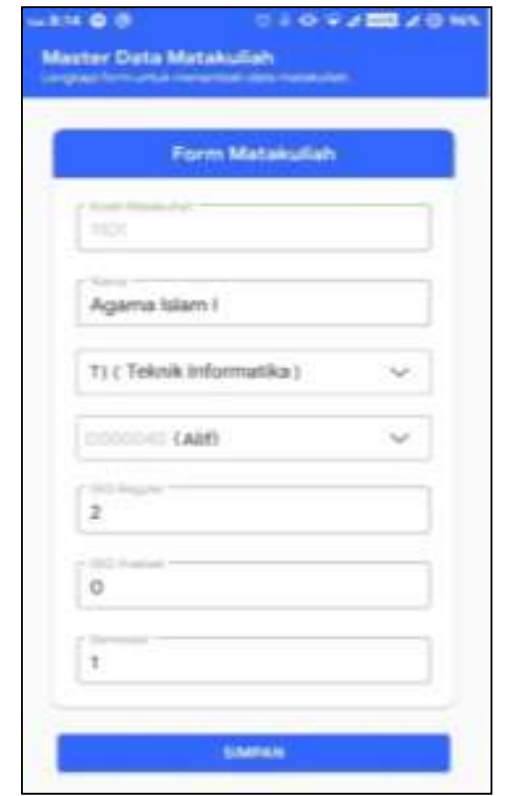

Gambar 8. Tampilan Input Matakuliah

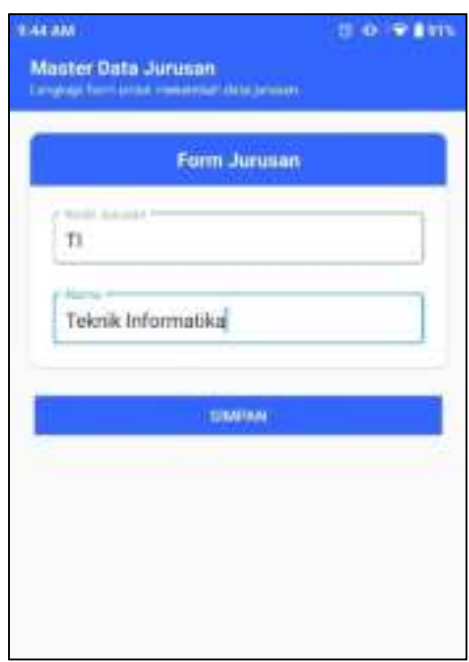

Gambar 10. Tampilan Input Jurusan 


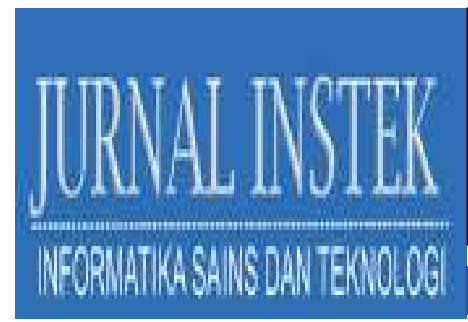

Volume 6 Nomor. 1, April 2021

P-ISSN : 2541-1179, E-ISSN : 2581-1711

Ojs :http://journal.uin-alauddin.ac.id/index.php/instek/index

Email : instek@uin-alauddin.ac.id

Pada halaman input data ini adalah media untuk memasukkan data-data terkait perkuliahan yang telah diperoleh berdasarkan wawancara yaitu input data dosen (gambar 7), matakuliah (gambar 8), ruang (gambar 9), jurusan (gambar 10).

\section{Tampilan Output (Hasil Penjadwalan)}

\begin{tabular}{|c|c|c|c|c|c|c|c|c|c|c|c|c|}
\hline \multirow[t]{2}{*}{ Jam } & \multicolumn{3}{|c|}{ R1 } & \multicolumn{3}{|c|}{$\mathrm{R} 2$} & \multicolumn{3}{|c|}{ R3 } & \multicolumn{3}{|c|}{ R4 } \\
\hline & 20 & Mataviren & Doses & Aer & Metabulah & Dosen & die & Matanilan & Dosen & Aur & Mnabuiats & Dossen \\
\hline \multicolumn{13}{|l|}{ at 00- of so } \\
\hline $0750 \cdot 08.49$ & & & & Th: & B! & D900003 & & & & & & \\
\hline $08.40 \cdot-1000$ & & & & The- & ai & 0500053 & & & & TM-2 & mow & Osoosos \\
\hline $02.30-70.20$ & & & & & & & & & & TMAs & PNowis & 0800000 \\
\hline $10.20 \cdot 11.10$ & & & & & & & & & & $\mathrm{tM}-\mathrm{z}$ & prows & 0500000 \\
\hline \multicolumn{13}{|l|}{$11.10 \cdot+12.00$} \\
\hline \multicolumn{13}{|l|}{$1200-1250$} \\
\hline \multicolumn{13}{|l|}{$2.50-13,40$} \\
\hline \multicolumn{13}{|l|}{$1240 \cdot 1430$} \\
\hline $1430-1520$ & $\pi-3$ & Por & D50002n. & & & & & & & & & \\
\hline $1520 \cdot 10.10$ & this & mon & Dsoosz2. & & & & & & & & & \\
\hline 1010.17 .00 & Th: & PXN & De000022 & & & & & & & & & \\
\hline \multirow[t]{2}{*}{ Jam } & \multicolumn{3}{|c|}{ RG00001 } & \multicolumn{3}{|c|}{$\mathrm{P} 2$} & \multicolumn{3}{|c|}{ RGG00012 } & \multicolumn{3}{|c|}{$\mathrm{PI}$} \\
\hline & aur & Monsituan & Denen & w & Matacilan & Doses & Aur & Manatuaten & Desen & ser & Metabulah & Doses \\
\hline of 00.0040 & & & & M-1 & AK & beosods & & & & & & \\
\hline at $30 \cdot \tan 40$ & & & & $m-1$ & Ak & osoosts & & & & & & \\
\hline \multicolumn{13}{|l|}{$08.40-00.30$} \\
\hline $06.30-1020$ & & & & & & & Tha & MLC & D500023 & & & \\
\hline $10.20 \cdot 11,10$ & & & & & & & $\pi \cdot 3$ & MLD & DS00023 & & & \\
\hline \multicolumn{13}{|l|}{11100.1200} \\
\hline $1200-12.50$ & & & & & & & & & & Thes & Med & Dosocess \\
\hline 1250.070 & & & & Tw3 & P19M & 0300035 & & & & Thes & MaD & posodes \\
\hline $12.40-14.30$ & & & & ths & PIM & D506430 & & & & Thes & Mab & osboms: \\
\hline $1+30-1920$ & & & & & & & & & & That & kas & atopost 4 \\
\hline $15.26 \cdot 10.10$ & & & & & & & & & & $\mathrm{nas}$ & kBo & OSDO0:4 \\
\hline $1010 \times 1730$ & & & & & & & & & & тын & k80 & 0050014 \\
\hline
\end{tabular}

Gambar 11. Tampilan Sampel Jadwal Perkuliahan 1 hari

Tampilan output dieksport oleh aplikasi ke dalam format pdf agar mudah dibaca. Dalam implementasi algoritma genetika pada aplikasi penyusunan jadwal menunjukkan hasil yang memuaskan. Dilihat dari laporan penjadwalan yang dihasilkan sudah tidak mengandung bentrokan pada jadwal.

\section{KESIMPULAN}

Penelitian ini mengimplementasikan algoritma genetika dalam sebuah aplikasi android. Penerapan algoritma genetika dalam penelitian ini menggunakan 6 kromosom sehingga mampu manghasilkan solusi optimal. Nilai crossover rate di atur sebesar $80 \%$, serta mutation rate dikontrol pada nilai 0.3 atau $30 \%$ agar 


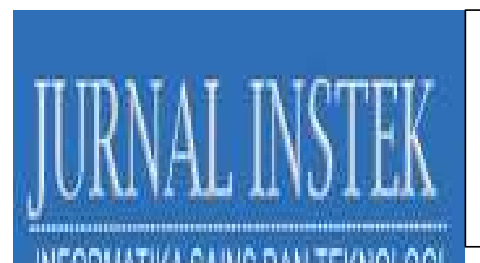

Volume 6 Nomor. 1, April 2021

P-ISSN : 2541-1179, E-ISSN : 2581-1711

Ojs :http://journal.uin-alauddin.ac.id/index.php/instek/index

Email : instek@uin-alauddin.ac.id

pemrosesan data tidak berlangsung lama. Berdasarkan hasil penelitian yang ditampilkan pada output program menunjukkan bahwa hasil penjadwalan dengan algoritma genetika mampu menghilangkan bentrokan jadwal yang terjadi ketika penyusunan dilakukan secara manual.

\section{DAFTAR PUSTAKA}

Lukas, S., Aribowo, A. dan Muchri, M. 2012.Solving Timetable Problem by Genetic Algorithm and Heuristic Search Case Study: University of Pelita Harapan Timetable. Real-World Applications of Genetic Algorithm. vol 9(4):19-21.

Shukla, A., Pandey, H. M. and Mehrotra, D. 2015. Comparative review of selection techniques in genetic algorithm. International Conference on Futuristic Trends on Computational Analysis and Knowledge Management (ABLAZE), Noida. hal 515-519.

Al-Jarrah, M.A., Al-Sawalqah, A.A. And Al-Hamdan3, S.F. 2017. Developing A Course Timetable System For Academic Departments Using Genetic Algorithm. Jordanian Journal of Computers and Information Technology. vol $3(1): 25-36$.

Yadav, S.L. and Sohal, A. 2017. Comparative Study of Different Selection Techniques in Genetic Algorithm. International Journal of Science and Mathematics Education, vol 6(3) :251-254.

Radliya, N.R. 2016. Pemodelan Sistem Penjadwalan Perkuliahan Menggunakan Algoritma Genetika . JAMIKA. vol 6(2) :19-27.

Ridwan, M. 2016. Prototype Sistem Pendukung Keputusan Untuk Penetapan Jadwal Kuliah Menggunakan Algoritma Genetika. Jurnal SYSTEMIC. vol 2(2) : 9-18.

Yusuf, A. \& Wiji, S. 2019. Sistem Pejadwalan Kuliah Meggunakan Metode Algoritma Genetika Pada Program Magister Fakultas Ekonomi Dan Bisnis. RAINSTEK : Jurnal Terapan Sains \& Teknologi. vol 1(1) : 40 - 47.

Laksono,A.T., Utami,M.C., Sugiarti, Y. 2016. Sistem Penjadwalan Kuliah Menggunakan Metode Algoritma Genetika (Studi Kasus: Fakultas Kedokteran Dan Kesehatan Universitas Muhammadiyah Jakarta). Studia Informatika: Jurnal Sistem Informasi . vol 9(2): 177-188.

Sari, Y., Alkaf, M., Wijaya,E.S., Soraya.S., Kartikasari, D.P. 2019. Optimasi Penjadwalan Mata Kuliah Menggunakan Metode Algoritma Genetika Dengan Teknik Tournament Selection. Jurnal Teknologi Informasi dan Ilmu Komputer (JTIIK), 6(1), : 85-92 . 